\title{
Effect of radiation on the Notch signaling pathway in osteoblasts
}

\author{
BING YANG ${ }^{1}$, QUAN TANG $^{1}$, JANINE POST $^{2}$, HUI ZHOU $^{3}$, XIAO-BIN HUANG ${ }^{4}$, \\ XIAO-DONG ZHANG ${ }^{1}$, QIN WANG ${ }^{1}$, YUAN-MING SUN ${ }^{1}$ and FEI-YUE FAN ${ }^{1}$ \\ ${ }^{1}$ Tianjin Key Laboratory of Molecular Nuclear Medicine, Institute of Radiation Medicine, Chinese Academy \\ of Medical Sciences and Peking Union Medical College, Tianjin 300192, P.R. China; ${ }^{2}$ Developmental \\ BioEngineering MIRA Institute for Biomedical Technology and Technical Medicine, University of Twente, \\ 7522NB Enschede, The Netherlands; ${ }^{3}$ School of Pharmacy, Tianjin Medical University, Tianjin 300070; \\ ${ }^{4}$ School of Life Sciences, Chongqing University, Chongqing 400045, P.R. China
}

Received November 21, 2012; Accepted December 28, 2012

DOI: $10.3892 /$ ijmm.2013.1255

\begin{abstract}
Notch signaling has been shown to be important in osteoblast differentiation. Therapeutic radiation has been shown to alter the skeletal system, yet little information is available on the changes in Notch signaling in irradiated osteoblasts. The purpose of this study was to analyze the effect of radiation therapy with 2 and 4 Gy on Notch signaling in osteoblasts. In order to assess the radiation damage on osteoblast differentiation, total RNA and protein were collected three days after exposure to radiation. The effects of radiation on Notch signaling at the early and terminal stages of osteoblastic MC3T3-E1 cell differentiation was analyzed by qRT-PCR and western blot analysis. Our study applied a previously established method to induce MC3T3-E1 cell differentiation into osteoblasts and osteoblast precursors. Our results showed that the expression of Notch receptors (Notch1-4), ligands (Jagged1, Jagged2 and Delta1), target of Notch signaling (Hes1) and markers (ALP, M-CSF, RANKL and OPG) were altered following 2 and 4 Gy of irradiation. The present research did not indicate a strong relationship between Notch1 regulation and suppression of osteoblast differentiation. We found Hes1 may play a role in the radiation effect on osteoblast differentiation. Our results indicate that radiated osteoblast precursors and osteoblasts promoted osteoclast differentiation and proliferation.
\end{abstract}

Correspondence to: Professor Yuan-ming Sun or Professor Fei-yue Fan, Tianjin Key Laboratory of Molecular Nuclear Medicine, Institute of Radiation Medicine, Chinese Academy of Medical Sciences and Peking Union Medical College, Tianjin 300192, P.R. China

E-mail: yuanmingsun@aol.com

E-mail: faithyfan@yahoo.com

Key words: Notch signaling, osteoblast, radiation, MC3T3 cells, differentiation

\section{Introduction}

Radiation therapy is an important and effective method for the treatment of tumors. However, this widely used treatment increases the occurrence of long-term side effects caused by radiation damage to normal tissues near the tumor. Sequelae in the skeleton and bone marrow can occur as late consequences for survivors following radiation therapy of cancer (1). Bones within the irradiated volume can absorb radiation doses, resulting in an increased fracture risk (2-6). In addition to bone fracture, demineralization of bone, thinning of bone, sclerosis, and loss of trabecular connections have been characterized as consequences of radiotherapy (7-10). Damage to osteoblasts and osteocytes is conceived to be a primary contributor to the reduced bone mineral density that is observed following irradiation $(7,8,10,11)$. Previous studies suggest that radiation can impair bone formation by inducing a decrease in osteoblast proliferation and differentiation, inducing cell-cycle arrest, reducing collagen production, and increasing sensitivity to apoptotic agents in vitro and in vivo (12-15).

During the radiation therapy of tumors, the absorbed dose in surrounding tissues can be substantial. Cancer patients receive daily doses (fractions) of 1.8-2.0 Gy targeted locally to the tumor and delivered over a period of a few minutes, with the total dose to the tumor ranging from 50 to $80 \mathrm{~Gy}$ or more. For large solar particle events (16) lasting 8-24 h, the whole body cumulative dose for protons could reach the 1-2 Gy level (1.0-2.0 Sv) depending upon the tissue site in the space radiation environment (17). It remains unknown what the effects of radiation on signaling pathways are, which is the topic of the present study.

Bone remodeling is a temporally and spatially regulated process that results in the coordinated resorption and formation of skeletal tissue (18). Bone remodeling occurs in basic multicellular units in which osteoclasts resorb bone and osteoblasts form newly synthesized matrix in a coordinated process that takes $\sim 4$ months. The number and function of osteoclasts and osteoblasts are regulated by extracellular and intracellular signals acting in a coordinated fashion that maintains skeletal 
homeostasis. The fate of mesenchymal cells and their differentiation into cells of the osteoblast lineage is tightly controlled by signaling molecules such as bone morphogenetic proteins (BMPs) and Wnt, which favor osteoblastogenesis, and by others such as Notch, which impairs osteoblast differentiation (19-21). In addition to bone construction, osteoblasts are involved in the regulation of bone resorption through receptor activator of nuclear factor- $\kappa \mathrm{B}$ (22) ligand (RANKL) and secretion of a soluble decoy receptor (osteoprotegerin, OPG). RANKL is a ligand for its receptor, RANK, and is a key factor in osteoclast differentiation and activation. OPG prevents osteoclast differentiation and activation and protects the skeleton from bone resorption by blocking RANK/RANKL interaction. In short, the balance between RANKL and OPG determines the formation and activity of osteoclasts (23).

Notch was first identified in Drosophila melanogaster, where its inactivation causes notches in the wing blade. The Notch signaling pathway is an evolutionarily conserved communication system. It mediates cell-cell interactions that are crucial for cell-fate determination, differentiation and many other biological processes. In mammals there are four receptors termed Notch1-4, which are single-pass transmembrane receptors. The ligands Delta/Serrate/Lag-2 (DSL) and Jagged1 and 2, and Delta1, 3, and 4 are single-pass transmembrane proteins expressed on the neighboring cells (24). Notch signaling relies on the surface interaction between the Notch receptor and membrane bound ligands in adjacent cells (25). Following ligand receptor interactions, Notch is cleaved and the Notch intracellular domain (NICD) is released (26). Hairy enhancer of split (Hes) and Hes related with YRPW motif (Hey) transcription factors are established targets of Notch signaling. Seven Hes proteins (Hes1-7) and three Hey proteins (Hey1, Hey2 and HeyL) have been identified, and all but Hes 2 and Hes3 are targets of Notch canonical signaling (27). Although Notch may act either as a suppressor or inducer of osteoblast differentiation in vitro, studies in transgenic murine models revealed that activation of Notch signaling arrests commitment of pluripotent precursors to the osteoblastic lineage and suppresses osteoblast differentiation (28).

Notch signaling has been shown to be important in the regulation of osteoblast differentiation, and therapeutic radiation has been shown to induce changes to the skeletal system. However, little information is available on the changes in Notch signaling in irradiated osteoblasts. The purpose of this study was thus to analyze the effect of radiation ( 2 and $4 \mathrm{~Gy}$ ) on the Notch pathway in vitro in differentiating osteoblasts. In order to assess the radiation damage on osteoblast differentiation, total RNA and protein were collected three days after radiation exposure. Furthermore, the effects of radiation on the Notch signaling pathway at the early and terminal stages of differentiation were analyzed by qRT-PCR and western blotting.

\section{Materials and methods}

Cell culture. MC3T3-E1 cells were obtained from the Cell Bank of the Institute of Basic Medicine at the Chinese Academy of Medical Science (Beijing, China) and maintained in $\alpha$-MEM supplemented with $1 \%$ L-glutamine and $10 \%$ heatinactivated FBS and $100 \mu \mathrm{g} / \mathrm{ml}$ of penicillin/streptomycin, in a humidified atmosphere of $5 \% \mathrm{CO}_{2}$ at $37^{\circ} \mathrm{C}$. The cells were split when the culture reached $80 \%$ confluency. The medium was changed every 3 days.

Induction of osteoblastogenic differentiation and radiation exposure. MC3T3-E1 cells were cultured in differentiation medium consisting of $\alpha$-MEM supplemented with $10 \% \mathrm{FBS}$, $50 \mu \mathrm{g} / \mathrm{ml}$ ascorbic acid (Sigma, St. Louis, MO, USA), and $10 \mathrm{mM} \beta$-glycerophosphate (Sigma) for 8 days to differentiate into osteoblast precursor cells (early stages of osteoblast differentiation) and 18 days to differentiate into osteoblast cells (terminal stage of osteoblast differentiation) (29). This supplemented medium is referred to as osteoblast differentiation medium or OBDM. It was refreshed every 3 days. The cells were exposed to 0,2 , or 4 Gy of $\gamma$-radiation on the fifth day (osteoblast precursor) or the fifteenth day (osteoblast). ${ }^{137} \mathrm{Cs}$ was used as a radiation source.

Alkaline phosphatase staining. To detect osteoblasts, alkaline phosphatase (ALP) staining was performed using the alkaline phosphatase kit (Nanjing Jiancheng Bioengineering Institute). For ALP staining, MC3T3-E1 cells were cultured with OBDM in 24-well plates. After 8 days and 18 days, ALP staining was performed according to the manufacturer's instructions.

$R N A$ extraction, reverse transcription and $q R T-P C R$ analysis. Total RNA was extracted using TRIzol reagent (Invitrogen, Carlsbad, CA, USA). First-strand cDNA was synthesized using the reverse transcription kit (Invitrogen) with total RNA $(1 \mu \mathrm{g}) . \mathrm{qRT}-\mathrm{PCR}$ analyses for Notch1, Notch2, Notch3, Notch4, Jagged1, Jagged2, Delta1, Runx2, Hes1, ALP, RANKL, OPG and M-CSF were performed using the CFX96 Touch $^{\mathrm{TM}}$ Realtime PCR detection system (Bio-Rad, Hercules, CA, USA). The reaction conditions were: $50^{\circ} \mathrm{C}$ for $2 \mathrm{~min}$ and $94^{\circ} \mathrm{C}$ for $3 \mathrm{~min}$, followed by 40 cycles of $94^{\circ} \mathrm{C}$ for $15 \mathrm{sec}, 60^{\circ} \mathrm{C}$ for $20 \mathrm{sec}$ and $72^{\circ} \mathrm{C}$ for $20 \mathrm{sec}$. The levels of $\beta$-actin mRNA were used as the internal control, and the gene-specific mRNA expression was normalized against $\beta$-actin expression. The sequences of the primers used in these analyses are listed in Table I.

Western blotting. Cells were lysed in M-PER Mammalian Protein Extraction Reagent (Thermo Scientific) containing protease inhibitors (Complete Ultra Mini EDTA-free protease inhibitor cocktail tablets, Roche). Protein samples were separated by electrophoresis in a $10 \%$ SDS-polyacrylamide gel and transferred onto a polyvinylidene difluoride (PVDF) membrane (Bio-Rad). The membrane was blocked with 5\% skimmed milk (BD). The following primary antibodies were used: mouse monoclonal antibody to $\beta$-actin (1:1000; Santa Cruz Biotechnology, Santa Cruz, CA, USA), mouse monoclonal antibody to Notch1 (1:1000; AbD Serotec), goat polyclonal antibody to Notch2 (1:500; Santa Cruz Biotechnology), goat polyclonal antibody to Jagged1 (1:500; Santa Cruz Biotechnology), goat polyclonal antibody to Runx2 (1:500; Santa Cruz Biotechnology), rabbit polyclonal antibody to Hes1 (1:1000; Santa Cruz Biotechnology), goat polyclonal antibody to M-CSF (1:500; Santa Cruz Biotechnology), goat polyclonal antibody to ALP (1:1000; Santa Cruz Biotechnology), rabbit polyclonal antibody to RANKL (1:500; Santa Cruz Biotechnology), mouse polyclonal antibody to OPG (1:500; Abcam) followed 


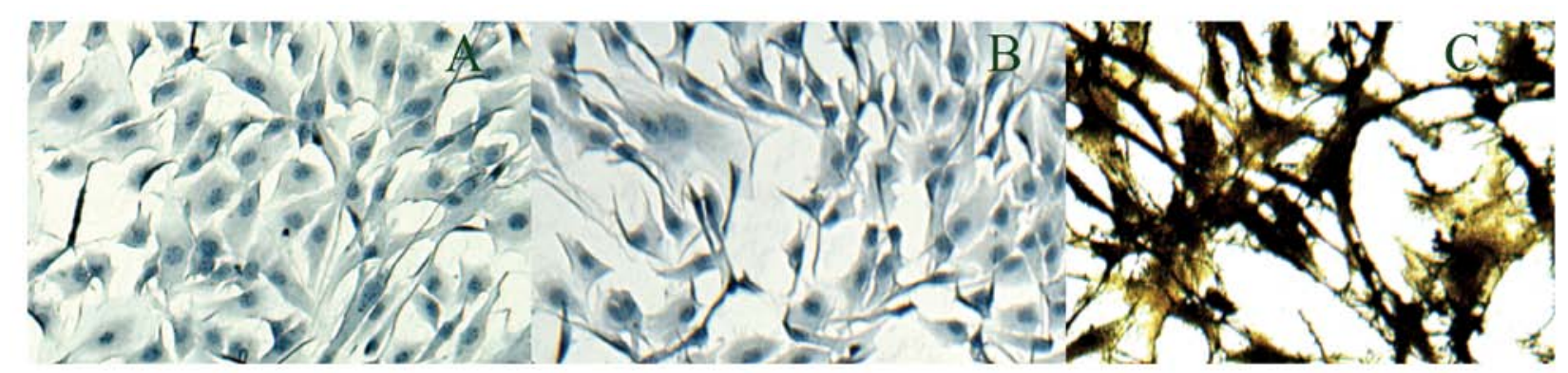

Figure 1. ALP staining (x10). (A) MC3T3-E1 cells; (B) MC3T3-E1 cells cultured with osteoblast differentiation medium for 8 days; (C) MC3T3-E1 cells cultured with osteoblast differentiation medium for 18 days.

Table I. Sequences of primers for quantitative real-time polymerase chain reaction.

Gene Sequence

Notch1

Forward: AGCCTCTCCACCAATACCTT Reverse: GGCTGGAGCTGTAAGTTCTG

Notch2

Forward: TTCACTCTCGAATGCAACTG Reverse: AGCGGCAATTGTAGGTATTG

Notch3 Forward: TTGGGAAATCTGCCTTACAC Reverse: GTCTCTTCCTTGCTGTCCTG

Notch4 Forward: TCCGGACTTTTAAGGCCAAA Reverse: TTCCCATTGCTGTGCATACTCT

Delta1 Forward: CTGAGGTGTAAGATGGAAGCG Reverse: CAACTGTCCATAGTGCAATGG

Jagged-1 Forward: CTCTGGAAACCTCTGTCAGC Reverse: TCAGGTGTGAGCAGTTCTTG

Jagged-2 Forward: AAGGACATACTCTACCAGTGC Reverse: ACGTCCTTGGTACTTCTGACG

Runx2 Forward: CGGCCCTCCCTGAACTCT Reverse: TGCCTGCCTGGGATCTGTA

Hes1 Forward: CCTCTGAGCACAGAAAGTCA Reverse: GCCGGGAGCTATCTTTCTTA

OPG Forward: ACAGAGACCAGGAAATGGTG Reverse: CTCTCCATCAAGGCAAGAAG

RANKL Forward: CCAAGATCTCTAACATGACG Reverse: CACCATCAGCTGAAGATAGT

M-CSF Forward: CATCGAGACCCTCAGACATT Reverse: GCTGCTTCTTTCATCCAGTC

ALP Forward: TCAGGGCAATGAGGTCACATC Reverse: CACAATGCCCACGGACTTC

$\beta$-actin Forward: GAGACCTTCAACACCCCAGCC Reverse: AATGTCACGCACGATTTCCC

by corresponding peroxidase-conjugated antibodies (1:5000) according to the manufacturer's instructions (ZSGB-BIO).
Infrared fluorescence of the secondary antibodies was read on a Bio-Rad ChemiDoc ${ }^{\mathrm{TM}}$ XRS+ system.

Statistical analysis. Data are presented as means $\pm \mathrm{SD}$. The data were compared using two-tailed unpaired Student's t-test (SPSS 17.0 for Windows). $\mathrm{P}<0.05$ was indicative of a statistically significant difference.

\section{Results}

In this study, we applied a previously established method to induce MC3T3-E1 cell differentiation into osteoblasts and osteoblast precursors. ALP is required for bone matrix mineralization and is used as an osteoblast differentiation marker (30). MC3T3-E1 cells exhibit ALP-positive staining (3) after 18 days of culture in OBDM, indicating that MC3T3-E1 cells successfully differentiated into osteoblasts (Fig. 1).

In order to determine the effect of radiation on the expression of Notch signaling receptors, mRNA expression of Notch1-4 was determined by qPCR, after 2 and 4 Gy of irradiation at the different differentiation stages. At the early stages of osteoblast differentiation, the mRNA expression level of Notch 2 and Notch 3 increased after exposure to 2 Gy of irradiation, and Notch1, Notch3 and Notch4 mRNA expression was upregulated after treatment with $4 \mathrm{~Gy}$ of irradiation. In addition, at the terminal stages of differentiation, $4 \mathrm{~Gy}$ of irradiation decreased the Notch 2 mRNA expression level and increased the mRNA expression level of Notch4; both 2- and 4-Gy irradiation increased Notch3 expression (Fig. 2). The protein expression levels of Notch1 and Notch2 were verified by western blotting (Fig. 5).

Three Notch ligands, Jagged1, Jagged2 and Delta1, were tested. Jagged 1 mRNA and protein expression levels were found to be upregulated at the early stage of differentiation in cells receiving $4 \mathrm{~Gy}$ of irradiation and at later stages when cells were treated with both 2 and $4 \mathrm{~Gy}$ of irradiation (Figs. 3 and 5). The mRNA expression of Jagged 2 increased at both the early and late stages following exposure to 2 and $4 \mathrm{~Gy}$ of irradiation. Additionally, for Delta1, the mRNA expression level only significantly increased at the terminal stage of osteoblast differentiation after $4 \mathrm{~Gy}$ of irradiation (Fig. 3).

The expression of Hes1, a known target of Notch signaling, was significantly upregulated at the terminal stages of MC3T3-E1 cells that received both 2 and 4 Gy of irradiation at the mRNA (Fig. 4) and protein levels (Fig. 5). This indicates that Notch signaling was increased in radiated cells. 
A

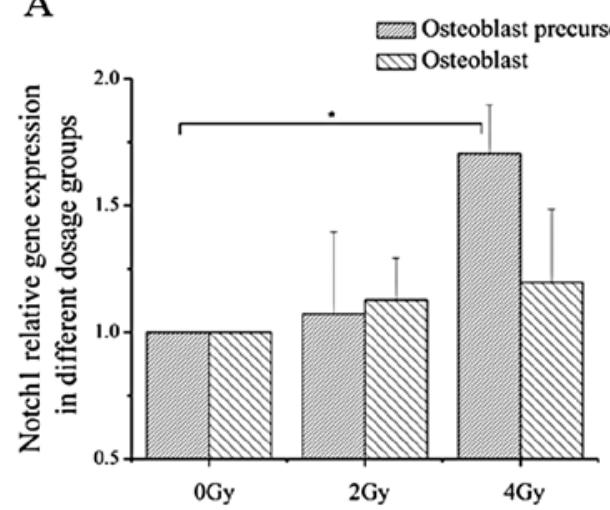

C

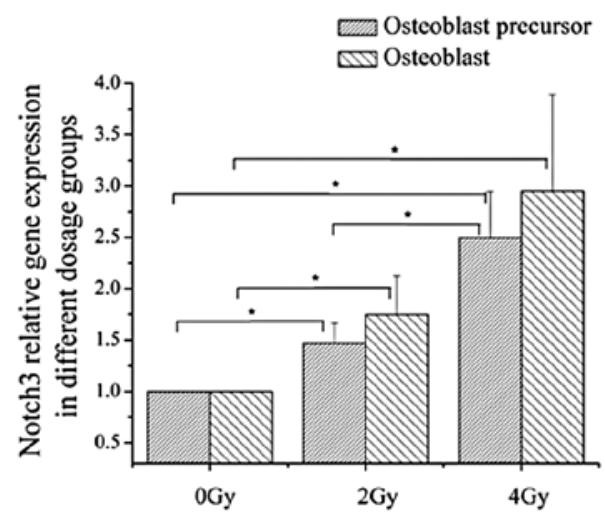

B

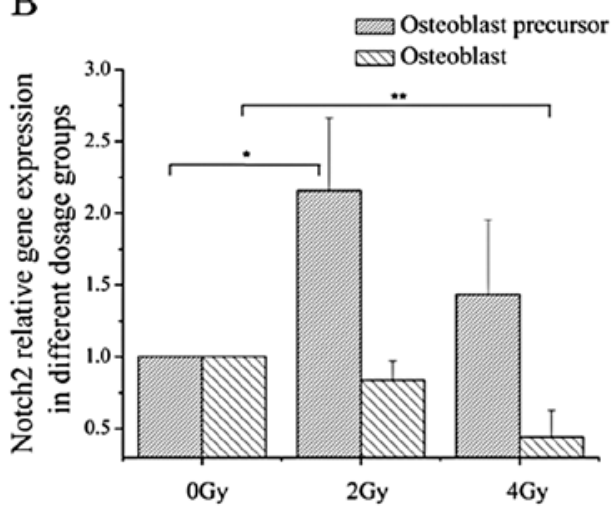

D

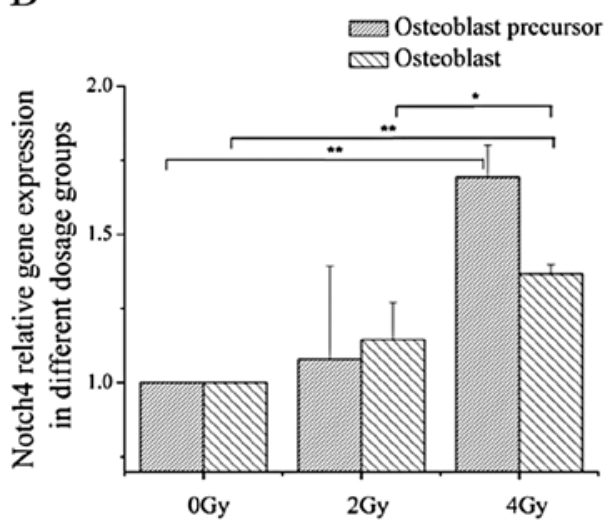

Figure 2. Relative expression of Notch receptors. The expression profiles of (A) Notch1, (B) Notch2, (C) Notch3 and (D) Notch4 were determined using the $2^{-\Delta \Delta C t}$ method. Each value represents the fold changes of each gene, respectively (mean $\pm \mathrm{SD}$ ) of triplicate cultures. ${ }^{*} \mathrm{P}<0.05,{ }^{* *} \mathrm{P}<0.01$.
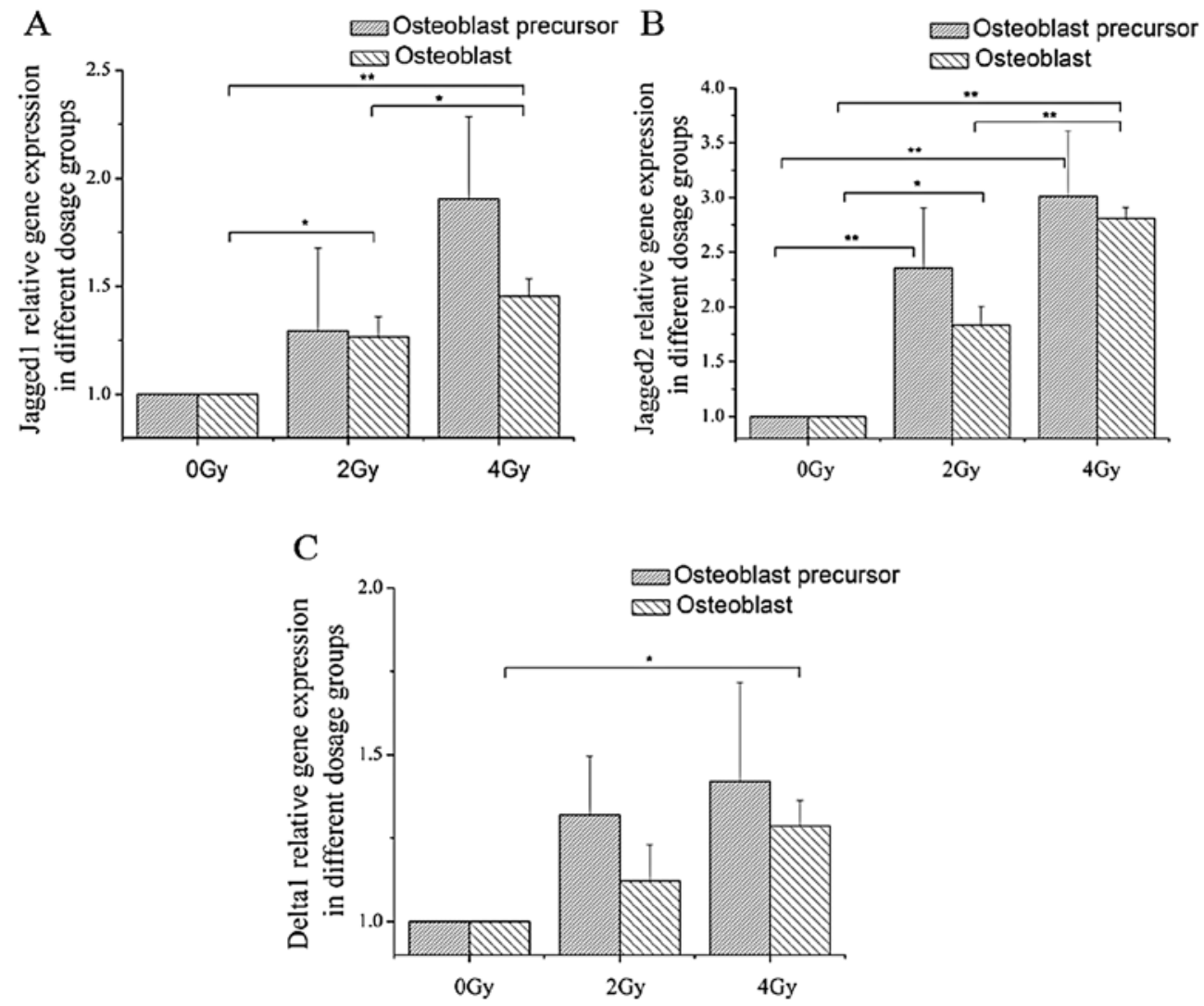

Figure 3. Relative expression of Notch ligands. The expression profiles of (A) Jagged1, (B) Jagged 2 and (C) Delta1 were determined using the $2^{-\Delta \Delta C t}$ method. Each value represents the fold changes of each gene, respectively (mean $\pm \mathrm{SD}$ ) of triplicate cultures. ${ }^{*} \mathrm{P}<0.05,{ }^{* *} \mathrm{P}<0.01$ 
A

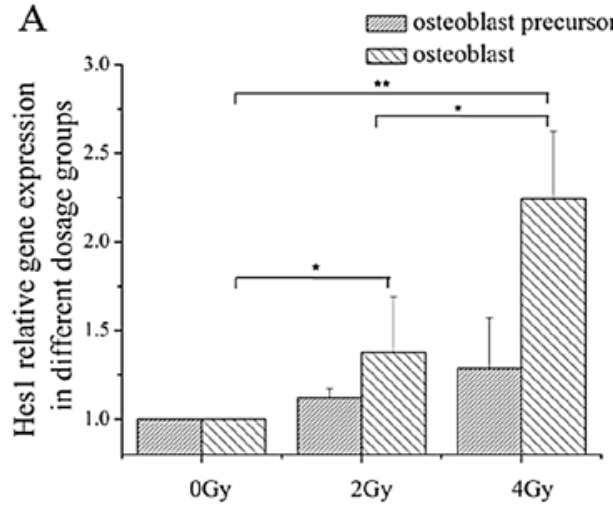

C

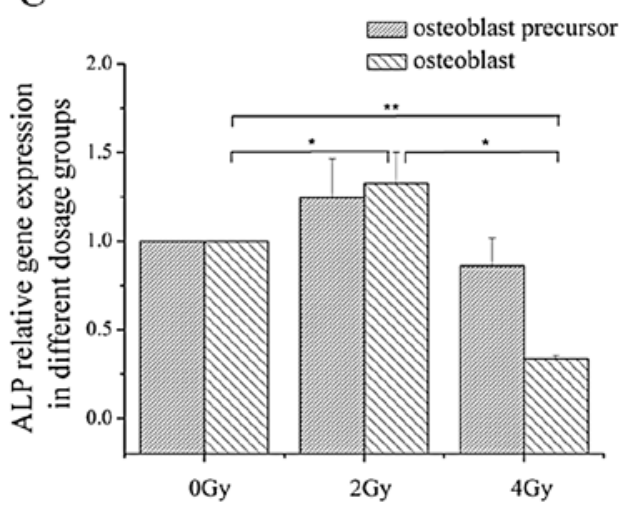

$\mathrm{E}$

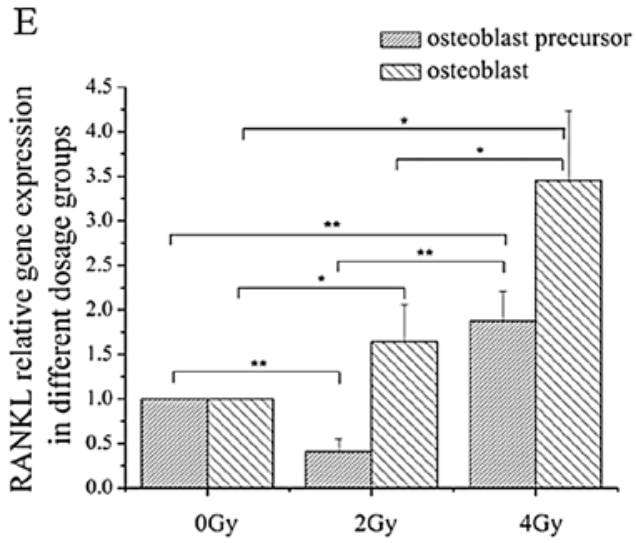

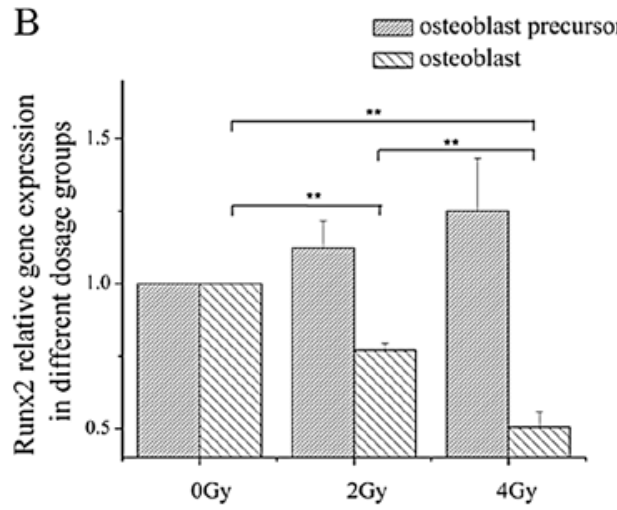

$\mathrm{D}$

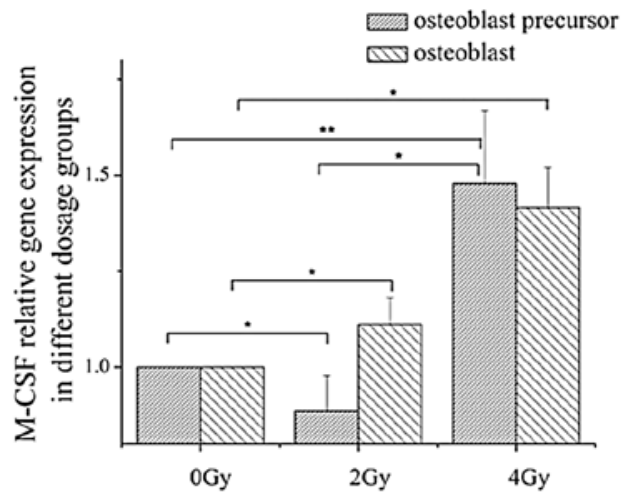

$\mathrm{F}$

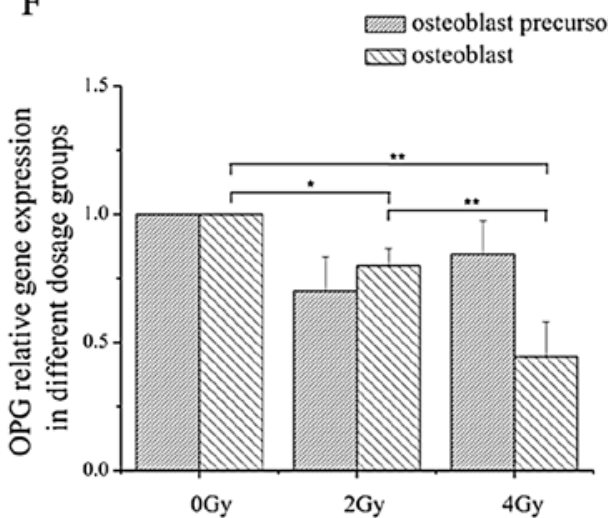

Figure 4. Relative expression of Hes1, Runx2, ALP, M-CSF, RANKL and OPG. The expression profiles of (A) Hes1, (B) Runx2, (C) ALP, (D) M-CSF, (E) RANKL and (F) OPG were determined using the $2^{-\Delta \Delta C t}$ method. Each value represents the fold changes of each gene, respectively (mean \pm SD) of triplicate cultures. ${ }^{*} \mathrm{P}<0.05,{ }^{* *} \mathrm{P}<0.01$.

Runx2 (Runt-related transcription factor, also called Cbfa1 or Pebp2aA), an important transactivator of Notch signaling, was repressed at the mRNA and protein levels after 2 and $4 \mathrm{~Gy}$ of irradiation following exposure during the terminal stage of differentiation (Figs. 4 and 5).

The expression of ALP, a marker for osteoblasts, was investigated. The ALP mRNA expression in the osteoblast precursors was not affected by 2 or $4 \mathrm{~Gy}$ of irradiation. However, 2 Gy of irradiation slightly induced ALP levels, and 4 Gy of radiation exposure repressed ALP mRNA expression at the terminal stage of osteoblast differentiation (Fig. 4). Radiation exposure of $4 \mathrm{~Gy}$ also decreased ALP protein expression at the terminal stage of osteoblast differentiation (Fig. 5). Although 2 Gy of irradiation decreased M-CSF mRNA expression at the early stages of differentiation, 2 Gy of irradiation increased
M-CSF levels at the late differentiation stages. Moreover, M-CSF expression was induced by 4 Gy of irradiation at both early and terminal stage (Fig. 4). However, the protein level of M-CSF increased at the early stages of differentiation after 2 and $4 \mathrm{~Gy}$ of radiation exposure. At the terminal stage of differentiation, the protein level of M-CSF increased following $4 \mathrm{~Gy}$ of radiation exposure. However, there was no increase in the protein level of M-CSF at the terminal stage of osteoblast differentiation following 2 Gy of radiation (Fig. 5).

RANKL and OPG expression, key regulators of osteoclast differentiation and function, was determined at different differentiation stages with 0,2 and $4 \mathrm{~Gy}$ of radiation exposure. The RANKL mRNA expression level in osteoblast precursors was repressed by 2 Gy of irradiation, but induced by 4 Gy of irradiation. In osteoblasts differentiated from MC3T3-E1 


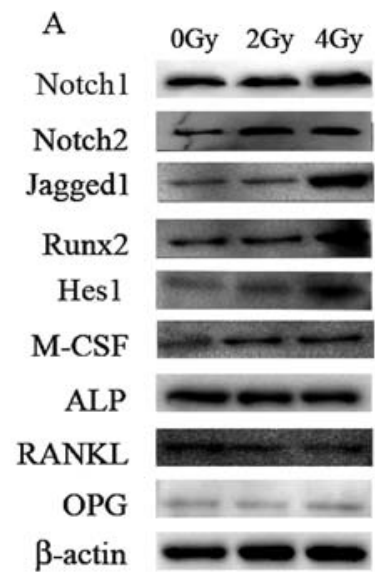

MC3T3-E1 osteoblast precursor
B

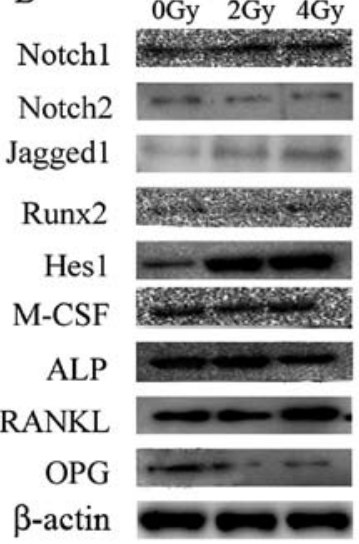

MC3T3-E1 osteoblast

Figure 5. Protein expression levels of Notch1, Notch2, Jagged1, Runx2, Hes1, M-CSF, ALP, RANKL and OPG. (A) Results of protein expression levels in osteoblast precursors by western blot analysis. (B) Results of protein expression levels in osteoblasts by western blot analysis.

cells, 2 and 4 Gy of irradiation successfully increased RANKL mRNA expression levels (Fig. 4). The protein level of RANKL was increased at the terminal stage of osteoblast differentiation after $4 \mathrm{~Gy}$ of radiation exposure and was decreased at the early and terminal stages of osteoblast differentiation following 2 Gy of irradiation. Of note, 2 and 4 Gy of irradiation did not change OPG mRNA and protein expression at the early stage of osteoblast differentiation, but impaired OPG levels at the terminal stage (Figs. 4 and 5).

\section{Discussion}

There is a high degree of structural homology in the intracellular domain of the four Notch receptors. Although the structural and functional properties of Notch1 have been characterized to a greater extent than those of other Notch receptors, their functional homology has not been explored in detail. It has been previously shown that elevated levels of Notch1 impaired osteoblastogenesis by inhibiting Wnt/ $\beta$ catenin signaling $(19,31)$. Wnt/ $\beta$-catenin signaling is required for osteoblastogenesis. Notch1 acts as a suppressor of osteoblast differentiation, but the different timing of overexpression of NICD is probably responsible for the differences in phenotype observed (32). NICD overexpression controlled by a $3.6-\mathrm{kb}$ fragment of the collagen type $1 \alpha 1$ (Coll $\alpha 1)$ promoter, which is expressed during the early stages of osteoblast differentiation, causes osteopenia due to decreased numbers of osteoblasts (33). Overexpression of NICD under the control of a $2.3-\mathrm{kb}$ fragment of the Coll $\alpha 1$ promoter, which is active in mature osteoblasts, causes an increase in osteoblasts synthesizing woven bone, possibly because of impaired terminal osteoblast differentiation, an effect mediated by the Notch canonical pathway $(34,35)$.

In the present study, both early and terminal osteoblast differentiation stages were investigated for the response to radiation exposure. Our results did not show a strong correlation between Notch1 regulation and suppression of osteoblast differentiation. $\gamma$-irradiation at 4 Gy increased the expression

of Notch1 in osteoblast precursors, the early osteoblast differentiation stage, but did not affect the expression level of ALP, an osteoblast marker. In addition, 4 Gy of $\gamma$-radiation of exposure decreased the ALP levels in osteoblasts at the terminal differentiation stage, but did not significantly increase Notch1 expression. It is widely recognized that Notch1 may present the main function of all four Notch receptors. However, we still suspect that Notch2-4 proteins could play a role in the regulation of skeletal development. The radiation effect on osteoblast differentiation could be an integrated result of the four Notch receptors or regulation by other molecular mechanisms. Although few studies concerning the function of Notch2-4 in osteoblasts exist, our laboratory investigated the radiation effects on Notch2-4 at the early and late stage of osteoblast differentiation.

We also investigated the radiation effects on three important Notch ligands, Jagged1, 2 and Delta1. Expression of the Notch ligand Jagged1 has been detected in osteoblastic cells in vivo and in vitro (31,36-40), and during bone regeneration (41). There are still controversies concerning the role of Jagged1 in osteoclastogenesis. Sethi et al demonstrated that Jagged1-expressing cells directly interact with osteoclast precursor cells to increase their activity by accelerating osteoclast differentiation and maturation (42). Bai et al demonstrated that Jagged1-expressing cells inhibit the differentiation of bone marrow macrophages to the osteoclast phenotype in the presence of RANKL (43). Nobta et al suggested that Jagged1 is capable of enhancing bone mineral deposition (41). Several studies have shown that osteoblasts expressing the Notch ligand Jagged1 are part of the hematopoietic stem cell (HSC) niche $(36,44)$. However, Mancini et al showed that HSC self-renewal and differentiation are independent of Jagged1dependent Notch signaling (45). Our study demonstrated that the level of Jagged-1 expression increased in osteoblasts after 2 and 4 Gy of radiation and in osteoblast precursors after 4 Gy of irradiation. Our results also showed their radiation induces Jagged 2 and Delta1 expression changes at the early and late stages of osteoblast differentiation. Even though the function of the Notch ligand in osteoblasts remains unclear, the ligands may play a role in osteoblasts after radiation exposure.

The expression of Hes1, one of the targets of Notch canonical signaling, was investigated after radiation. Hes1 plays an important role in osteoblast differentiation and osteoblast-osteoclast interaction. Hes1 overexpression impaired osteoblastogenesis in vitro, and Hes1-overexpressing transgenic osteoblasts enhanced the resorptive activity of co-cultured osteoclast precursors (46). Additionally, Hes1 binds to the osteocalcin promoter and suppresses transactivation of osteocalcin (47). This indicates that Hes1 could suppress osteoblastogenesis and play a positive role in osteoclastogenesis. We observed that 4 Gy of radiation increased Hes1 expression by 2.2-fold. Of note, the expression level of ALP decreased accompanied by increased Hes1 levels in osteoblasts after 4 Gy of irradiation. Therefore, we suspect that 4 Gy of radiation can inhibit osteoblast differentiation at the terminal stage by upregulating Hes1 expression. The upregulation of Hes1 in osteoblasts indicated that Notch signaling was more active after 2 and 4 Gy of irradiation. The components in Notch signaling were not directly transcribed upon radiation treatment, but this does not mean that the pathway was not affected by irradiation. 
Table II. RANKL, OPG and M-CSF mRNA and protein expression alterations at the early and terminal differentiation stages following 2 and 4 Gy of irradiation.

2-Gy irradiation

\begin{tabular}{cc}
\hline Early osteoblast & Terminal osteoblast \\
differentiation stage & differentiation stage
\end{tabular}

4-Gy irradiation

\begin{tabular}{cc}
\hline Early osteoblast & Terminal osteoblast \\
differentiation stage & differentiation stage
\end{tabular}

\begin{abstract}
RANKL
mRNA level

Protein level

OPG

mRNA level

Protein level

\section{$\mathrm{M}-\mathrm{CSF}$}

mRNA level

Protein level
\end{abstract}

\section{$\downarrow$}

$\downarrow$

$-$

$-$ $\uparrow$

$-$

$\downarrow$

$\uparrow$
Runx2 is an essential transactivator for osteoblast differentiation and bone formation and is crucial for regulating the expression of bone-specific genes $(48,49)$. Runx2 has been shown to induce ALP activity and mineralization in immature mesenchymal cells and osteoblastic cells in vitro (50-52). Runx2 is an inhibitor of the Notch1 signaling pathway during normal osteoblast differentiation by physically interacting with Notch1-IC and disrupting the Notch1-IC-RBP-Jk transcription complex (53). We found that Runx 2 expression is repressed at the terminal stages of osteoblast differentiation after exposure to 2 and $4 \mathrm{~Gy}$ of irradiation. Additionally, 4 Gy of irradiation impaired both Runx 2 and ALP expression at the late stage of differentiation. We suspected that $4 \mathrm{~Gy}$ of irradiation suppressed ALP expression levels and osteoblast differentiation at the terminal stage by inhibition of Runx 2 expression. Both 2 and 4 Gy of irradiation impaired Runx 2 expression, but only 4 Gy of irradiation decreased ALP expression. However, 2 Gy of irradiation did not repress, but slightly increased ALP expression at the late stage of osteoblast differentiation. This result indicated that the increased ALP expression at the early stage of differentiation after $2 \mathrm{~Gy}$ of irradiation was not induced by Runx 2 .

Irradiated osteoblasts may promote osteoclast differentiation and proliferation mediated by RANKL/OPG and macrophage colony stimulating factor (M-CSF). RANKL, OPG and M-CSF are the key regulators of bone resorption and act directly on osteoclast precursors. M-CSF produced by osteoblast cells is required for survival of cells in the macrophage-osteoclast lineage, and appears to be essential for the proliferation and differentiation of osteoclast progenitors (54-58). In addition to M-CSF, RANKL has been identified as a key cytokine that regulates osteoclastogenesis and bone resorption (22,59-61).

Activated osteoblasts support osteoclast formation and differentiation by expressing M-CSF and RANKL, but they also inhibit this process through expression of OPG, which binds to and inactivates RANKL. Changes in RANKL, OPG and M-CSF mRNA and protein expression in early and terminally differentiated osteoblasts after 2 and 4 Gy of irradiation are listed in Table II. Our results showed that osteoblasts receiving 2 and $4 \mathrm{~Gy}$ of irradiation at the terminal differentiation stage undergo osteoclast differentiation and proliferation by increased RANKL and M-CSF expression and decreased OPG expression. Compared with the late stage of osteoblast differentiation, the radiation effect on the early stage of osteoblast differentiation was more pronounced. Irradiation at 2 Gy decreased RANKL mRNA and protein expression levels and showed no significant changes in OPG levels at the early stage of osteoblast differentiation. Radiation exposure at 2 Gy induced M-CSF downregulation at the mRNA level, but upregulation at the protein level at the early stage of osteoblast differentiation. Even more, $4 \mathrm{~Gy}$ of irradiation increased M-CSF mRNA and protein expression and showed no significant changes in OPG level in early stage osteoblasts. Radiation exposure at $4 \mathrm{~Gy}$ induced RANKL upregulation at the mRNA level, while RANKL was downregulated at the protein level at the early stage of osteoblast differentiation. Irradiation at $4 \mathrm{~Gy}$ stimulated osteoclast differentiation and functioned through increasing M-CSF and RANKL levels. Radiated osteoblasts may play a role in radiation-induced bone loss. Considering the radiation effect on Notch signaling and its important role in osteoblast regulation, we suspect that Notch signaling plays an important role in osteoblast-osteoclast communication.

Many studies have reported that Notch signaling is vital to osteoblast development and skeletal remodeling by loss and gain methods. However, radiation may be more complicated and could cause a serial of changes in Notch signaling. Although our data suggest that Notch1 may not be an important contribution to the radiation effect of osteoblast differentiation, we still need to understand how Notch receptors function together when subjected to external stimuli, such as exposure to radiation. This study reports the changes in Notch signaling following radiation. Our study did not show a strong relation between the upregulation of Notch1 expression and suppression of osteoblast differentiation. We found that Hes1 plays a role in the radiation effect on osteoblast differentiation. The components in Notch signaling were not directly transcribed upon radiation treatment, but this does not mean 
that the pathway was not affected by irradiation. Moreover, our result indicated that irradiated osteoblasts promote osteoclast differentiation and proliferation. Our findings aid in the understanding of the mechanism of the Notch signaling pathway in radiation-impaired osteoblastogenesis.

\section{Acknowledgements}

The authors thank Dr Liqing Du and Dr XiaoChun Wang for the helpful discussion. This study was supported by grants from the National Nature Science Foundation of China (no. 30970867) (http://www.nsfc.gov.cn).

\section{References}

1. Parker RG and Berry HC: Late effects of therapeutic irradiation on the skeleton and bone marrow. Cancer 37 (Suppl 2): 1162-1171, 1976.

2. Baxter NN, Habermann EB, Tepper JE, Durham SB and Virnig BA: Risk of pelvic fractures in older women following pelvic irradiation. JAMA 294: 2587-2593, 2005.

3. Brown SA and Guise TA: Cancer treatment-related bone disease. Crit Rev Eukaryot Gene Expr 19: 47-60, 2009.

4. Guise TA: Bone loss and fracture risk associated with cancer therapy. Oncologist 11: 1121-1131, 2006.

5. Florin TA, Fryer GE, Miyoshi T, Weitzman M, Mertens AC, Hudson MM, Sklar CA, Emmons K, Hinkle A, Whitton J, Stovall M, Robison LL and Oeffinger KC: Physical inactivity in adult survivors of childhood acute lymphoblastic leukemia: a report from the childhood cancer survivor study. Cancer Epidemiol Biomarkers Prev 16: 1356-1363, 2007.

6. Oeffinger KC, Mertens AC, Sklar CA, Kawashima T, Hudson MM, Meadows AT, Friedman DL, Marina N, Hobbie W, Kadan-Lottick NS, Schwartz CL, Leisenring W and Robison LL: Childhood Cancer Survivor Study: chronic health conditions in adult survivors of childhood cancer. $\mathrm{N}$ Engl $\mathrm{J}$ Med 355: 1572-1582, 2006.

7. Ergün $\mathrm{H}$ and Howland WJ: Postradiation atrophy of mature bone. CRC Crit Rev Diagn Imaging 12: 225-243, 1980.

8. Hopewell JW: Radiation-therapy effects on bone density. Med Pediatr Oncol 41: 208-211, 2003.

9. Howland WJ, Loeffler RK, Starchman DE and Johnson RG: Postirradiation atrophic changes of bone and related complications. Radiology 117: 677-685, 1975.

10. Mitchell MJ and Logan PM: Radiation-induced changes in bone. Radiographics 18: 1125-1136, 1998.

11. Sams A: The effect of $2000 \mathrm{r}$ of X-rays on the internal structure of the mouse tibia. Int J Radiat Biol Relat Stud Phys Chem Med 11: 51-68, 1966.

12. Dudziak ME, Saadeh PB, Mehrara BJ, Steinbrech DS, Greenwald JA, Gittes GK and Longaker MT: The effects of ionizing radiation on osteoblast-like cells in vitro. Plast Reconstr Surg 106: 1049-1061, 2000.

13. Gal TJ, Munoz-Antonia T, Muro-Cacho CA and Klotch DW: Radiation effects on osteoblasts in vitro: a potential role in osteoradionecrosis. Arch Otolaryngol Head Neck Surg 126: 1124-1128, 2000.

14. Szymczyk KH, Shapiro IM and Adams CS: Ionizing radiation sensitizes bone cells to apoptosis. Bone 34: 148-156, 2004.

15. Sakurai T, Sawada Y, Yoshimoto M, Kawai M and Miyakoshi J: Radiation-induced reduction of osteoblast differentiation in C2C12 cells. J Radiat Res 48: 515-521, 2007.

16. Geblinger D, Zink C, Spencer ND, Addadi L and Geiger B: Effects of surface microtopography on the assembly of the osteoclast resorption apparatus. J R Soc Interface 9: 1599-1608, 2012.

17. Willey JS, Lloyd SA, Nelson GA and Bateman TA: Space radiation and bone loss. Gravit Space Biol Bull 25: 14-21, 2011.

18. Canalis E, Giustina A and Bilezikian JP: Mechanisms of anabolic therapies for osteoporosis. N Engl J Med 357: 905-916, 2007.

19. Deregowski V, Gazzerro E, Priest L, Rydziel S and Canalis E: Notch 1 overexpression inhibits osteoblastogenesis by suppressing Wnt/beta-catenin but not bone morphogenetic protein signaling. J Biol Chem 281: 6203-6210, 2006.

20. Gazzerro E and Canalis E: Bone morphogenetic proteins and their antagonists. Rev Endocr Metab Disord 7: 51-65, 2006.
21. Krishnan V, Bryant HU and Macdougald OA: Regulation of bone mass by Wnt signaling. J Clin Invest 116: 1202-1209, 2006.

22. Wong BR, Rho J, Arron J, Robinson E, Orlinick J, Chao M, Kalachikov S, Cayani E, Bartlett FS III, Frankel WN, Lee SY and Choi Y: TRANCE is a novel ligand of the tumor necrosis factor receptor family that activates c-Jun N-terminal kinase in T cells. J Biol Chem 272: 25190-25194, 1997.

23. Caetano-Lopes J, Canhão H and Fonseca JE: Osteoblasts and bone formation. Acta Reumatol Port 32: 103-110, 2007.

24. Zanotti S and Canalis E: Notch regulation of bone development and remodeling and related skeletal disorders. Calcif Tissue Int 90: 69-75, 2012 .

25. Hori K, Sen A, Kirchhausen T and Artavanis-Tsakonas S: Regulation of ligand-independent Notch signal through intracellular trafficking. Commun Integr Biol 5: 374-376, 2012.

26. Schroeter EH, Kisslinger JA and Kopan R: Notch-1 signalling requires ligand-induced proteolytic release of intracellular domain. Nature 393: 382-386, 1998.

27. Iso T, Kedes L and Hamamori Y: HES and HERP families: multiple effectors of the Notch signaling pathway. J Cell Physiol 194: 237-255, 2003.

28. Zanotti S and Canalis E: Notch and the skeleton. Mol Cell Biol 30: 886-896, 2010.

29. Quarles LD, Yohay DA, Lever LW, Caton R and Wenstrup RJ: Distinct proliferative and differentiated stages of murine MC3T3-E1 cells in culture: an in vitro model of osteoblast development. J Bone Miner Res 7: 683-692, 1992.

30. Murshed M, Harmey D, Millán JL, McKee MD and Karsenty G: Unique coexpression in osteoblasts of broadly expressed genes accounts for the spatial restriction of ECM mineralization to bone. Genes Dev 19: 1093-1104, 2005.

31. Sciaudone M, Gazzerro E, Priest L, Delany AM and Canalis E: Notch 1 impairs osteoblastic cell differentiation. Endocrinology 144: 5631-5639, 2003.

32. Kalajzic I, Kalajzic Z, Kaliterna M, Gronowicz G, Clark SH, Lichtler AC and Rowe D: Use of type I collagen green fluorescent protein transgenes to identify subpopulations of cells at different stages of the osteoblast lineage. J Bone Miner Res 17: 15-25, 2002.

33. Zanotti S, Smerdel-Ramoya A, Stadmeyer L, Durant D, Radtke F and Canalis E: Notch inhibits osteoblast differentiation and causes osteopenia. Endocrinology 149: 3890-3899, 2008.

34. Tao J, Chen S, Yang T, Dawson B, Munivez E, Bertin T and Lee B: Osteosclerosis owing to Notch gain of function is solely Rbpj-dependent. J Bone Miner Res 25: 2175-2183, 2010.

35. Engin F, Yao Z, Yang T, Zhou G, Bertin T, Jiang MM, Chen Y, Wang L, Zheng H, Sutton RE, Boyce BF and Lee B: Dimorphic effects of Notch signaling in bone homeostasis. Nat Med 14: 299-305, 2008

36. Calvi LM, Adams GB, Weibrecht KW, Weber JM, Olson DP, Knight MC, Martin RP, Schipani E, Divieti P, Bringhurst FR, Milner LA, Kronenberg HM and Scadden DT: Osteoblastic cells regulate the haematopoietic stem cell niche. Nature 425: 841-846, 2003.

37. Pereira RM, Delany AM, Durant D and Canalis E: Cortisol regulates the expression of Notch in osteoblasts. J Cell Biochem 85: 252-258, 2002.

38. Schnabel M, Fichtel I, Gotzen L and Schlegel J: Differential expression of Notch genes in human osteoblastic cells. Int J Mol Med 9: 229-232, 2002.

39. Luo B, Aster JC, Hasserjian RP, Kuo F and Sklar J: Isolation and functional analysis of a cDNA for human Jagged2, a gene encoding a ligand for the Notch1 receptor. Mol Cell Biol 17: 6057-6067, 1997.

40. Dallas DJ, Genever PG, Patton AJ, Millichip MI, McKie N and Skerry TM: Localization of ADAM10 and Notch receptors in bone. Bone 25: 9-15, 1999.

41. Nobta M, Tsukazaki T, Shibata Y, Xin C, Moriishi T, Sakano S, Shindo $\mathrm{H}$ and Yamaguchi A: Critical regulation of bone morphogenetic protein-induced osteoblastic differentiation by Delta1/Jagged1-activated Notch1 signaling. J Biol Chem 280: $15842-15848,2005$.

42. Sethi N, Dai X, Winter CG and Kang Y: Tumor-derived JAGGED1 promotes osteolytic bone metastasis of breast cancer by engaging notch signaling in bone cells. Cancer Cell 19: 192-205, 2011.

43. Bai S, Kopan R, Zou W, Hilton MJ, Ong CT, Long F, Ross FP and Teitelbaum SL: NOTCH1 regulates osteoclastogenesis directly in osteoclast precursors and indirectly via osteoblast lineage cells. J Biol Chem 283: 6509-6518, 2008. 
44. Zhang J, Niu C, Ye L, Huang H, He X, Tong WG, Ross J, Haug J, Johnson T, Feng JQ, Harris S, Wiedemann LM, Mishina Y and $\mathrm{Li}$ L: Identification of the haematopoietic stem cell niche and control of the niche size. Nature 425: 836-841, 2003.

45. Mancini SJ, Mantei N, Dumortier A, Suter U, MacDonald HR and Radtke F: Jagged1-dependent Notch signaling is dispensable for hematopoietic stem cell self-renewal and differentiation. Blood 105: 2340-2342, 2005.

46. Zanotti S, Smerdel-Ramoya A and Canalis E: HES1 (hairy and enhancer of split 1) is a determinant of bone mass. J Biol Chem 286: 2648-2657, 2011

47. Zhang Y, Lian JB, Stein JL, van Wijnen AJ and Stein GS: The Notch-responsive transcription factor Hes-1 attenuates osteocalcin promoter activity in osteoblastic cells. J Cell Biochem 108: 651-659, 2009.

48. Ito Y: Oncogenic potential of the RUNX gene family: 'overview'. Oncogene 23: 4198-4208, 2004

49. Levanon D, Negreanu V, Bernstein Y, Bar-Am I, Avivi L and Groner Y: AML1, AML2, and AML3, the human members of the runt domain gene-family: cDNA structure, expression, and chromosomal localization. Genomics 23: 425-432, 1994.

50. Banerjee C, McCabe LR, Choi JY, Hiebert SW, Stein JL, Stein GS and Lian JB: Runt homology domain proteins in osteoblast differentiation: AML3/CBFA1 is a major component of a bone-specific complex. J Cell Biochem 66: 1-8, 1997.

51. Ducy P, Zhang R, Geoffroy V, Ridall AL and Karsenty G: Osf2/Cbfa1: a transcriptional activator of osteoblast differentiation. Cell 89: 747-754, 1997.

52. Harada H, Tagashira S, Fujiwara M, Ogawa S, Katsumata T, Yamaguchi A, Komori T and Nakatsuka M: Cbfal isoforms exert functional differences in osteoblast differentiation. J Biol Chem 274: 6972-6978, 1999.

53. Ann EJ, Kim HY, Choi YH, Kim MY, Mo JS, Jung J, Yoon JH, Kim SM, Moon JS, Seo MS, Hong JA, Jang WG, Shore P, Komori T, Koh JT and Park HS: Inhibition of Notch1 signaling by Runx 2 during osteoblast differentiation. J Bone Miner Res 26 317-330, 2011.
54. Yoshida H, Hayashi S, Kunisada T, Ogawa M, Nishikawa S, Okamura H, Sudo T, Shultz LD and Nishikawa S: The murine mutation osteopetrosis is in the coding region of the macrophage colony stimulating factor gene. Nature 345: 442-444, 1990.

55. Lagasse E and Weissman IL: Enforced expression of Bcl-2 in monocytes rescues macrophages and partially reverses osteopetrosis in op/op mice. Cell 89: 1021-1031, 1997.

56. Takahashi N, Udagawa N, Akatsu T, Tanaka H, Isogai Y and Suda T: Deficiency of osteoclasts in osteopetrotic mice is due to a defect in the local microenvironment provided by osteoblastic cells. Endocrinology 128: 1792-1796, 1991.

57. Hattersley G, Owens J, Flanagan AM and Chambers TJ: Macrophage colony stimulating factor (M-CSF) is essential for osteoclast formation in vitro. Biochem Biophys Res Commun 177: 526-531, 1991

58. Tanaka S, Takahashi N, Udagawa N, Tamura T, Akatsu T, Stanley ER, Kurokawa T and Suda T: Macrophage colonystimulating factor is indispensable for both proliferation and differentiation of osteoclast progenitors. J Clin Invest 91: 257-263, 1993.

59. Yasuda H, Shima N, Nakagawa N, Yamaguchi K, Kinosaki M, Mochizuki S, Tomoyasu A, Yano K, Goto M, Murakami A, Tsuda E, Morinaga T, Higashio K, Udagawa N, Takahashi N and Suda T: Osteoclast differentiation factor is a ligand for osteoprotegerin/osteoclastogenesis-inhibitory factor and is identical to TRANCE/RANKL. Proc Natl Acad Sci USA 95: 3597-3602, 1998.

60. Lacey DL, Timms E, Tan HL, Kelley MJ, Dunstan CR, Burgess T, Elliott R, Colombero A, Elliott G, Scully S, Hsu H, Sullivan J, Hawkins N, Davy E, Capparelli C, Eli A, Qian YX, Kaufman S, Sarosi I, Shalhoub V, Senaldi G, Guo J, Delaney J and Boyle WJ: Osteoprotegerin ligand is a cytokine that regulates osteoclast differentiation and activation. Cell 93: 165-176, 1998.

61. Anderson DM, Maraskovsky E, Billingsley WL, Dougall WC, Tometsko ME, Roux ER, Teepe MC, DuBose RF, Cosman D and Galibert L: A homologue of the TNF receptor and its ligand enhance T-cell growth and dendritic-cell function. Nature 390: 175-179, 1997. 